\title{
Gabapentin completely neutralized the acute morphine activation in the rat hypothalamus: a c-Fos study
}

\author{
Jamil Ahsan Kazi ${ }^{*, 1}$ \& Zatilfarihiah Rasdi ${ }^{1}$ \\ 1 Universiti Teknologi MARA (UiTM), Faculty of Dentistry, Centre of Studies for Preclinical Science, Jalan Hospital, 47000 SUNGAI \\ BULOH, Selangor, Malaysia \\ *Author for correspondence: Tel.: (+603) 6126 6511; Fax: 603-61266103; kazi@salam.uitm.edu.my, kaziahsanjamil@gmail.com
}

\begin{abstract}
Aim: The molecular mechanism of gabapentin (GBP)-morphine combinational function and its neuroanatomical sites of action to prevent, to neutralize morphine side effects and also the enhancement its analgesic effect of morphine is unknown. Methods: Morphine $(10 \mathrm{mg} / \mathrm{kg})$, saline, co-injection: GBP $(150 \mathrm{mg} / \mathrm{kg})$ with morphine $(10 \mathrm{mg} / \mathrm{kg})$ were injected by intraperitoneal injection in rats under deep anaesthesia. C-Fos immunohistochemistry technique was used to locate c-Fos expression in rat hypothalamus. Results: Gabapentin in combination with morphine significantly $(p<0.01)$ attenuated the acute morphine induced c-Fos immunoreactive neuron in hypothalamus. Conclusion: GBP neutralized the morphine sensitization in rat hypothalamus. GBP might neuromodulate and or antagonize the receptor regulatory machinery of morphine sensitization circuit which might work for drug discovery of morphine abuse.
\end{abstract}

First draft submitted: 14 November 2018; Accepted for publication: 22 February 2019; Published online: 24 May 2019

Keywords: C-Fos $\bullet$ Gabapentin $\bullet$ hypothalamus $\bullet$ immunohistochemistry $\bullet$ morphine $\bullet$ rat

Physical dependence and tolerance occur due to chronic exposure to opioid (morphine) which in turn reduces their analgesic potential [1]. It is well established that use of opiate for chronic treatment induces neuroadaptations in intracellular signaling molecules at multiple levels [2]. Thus, the development of opiate tolerance and dependence could possibly be modulated by regulating the intracellular messenger pathways, neurotransmitter and ion channels [3-6].

GABA analog anticonvulsant, gabapentin (Neurontin) has been proven and use effectively for antinociception in a wide range of animal models [7]. A new animal model of neuralgia study [8] showed that systemic and spinal administration of gabapentin effectively relieved allodynia. In addition, GBP also showed effective for the treatment of anxiety [9]. GBP shows very acceptable side effects: it is well tolerated, shows lack of drug interaction and drug dependence [7]. Studies documented that as an analgesic GBP exerts its effect at both the spinal and supraspinal levels [10-13]. Gabapentin does not exert its antihyperalgesic effect through opiate pathways [14,15]. Chronic administration of GBP does not cause morphine tolerance. More importantly, opiate tolerance does not affect the antinociceptive potential of gabapentin. Thus, GBP reduced the therapeutic requirement for morphine consumption. Moreover, GBP reverse as well as blocks the antinociceptive opioids tolerance. Moreover, GBP prevent the withdrawal symptoms of morphine [14-17].

Gabapentin and morphine combinational administration obtained better analgesic effect at lower doses of each drug than either as a single agent [18-20]. Studies [21,22] reported that GBP potentially effective in the treatment of morphine withdrawal and morphine dependence. Furthermore, the combined use of GBP and morphine administration reported maximum therapeutic potential $[18,20,23,24]$. More importantly, the exact molecular mechanism of GBP-morphine combined action in therapeutic effectiveness is unknown.

c-fos is an immediate early genes. Its protein product the c-Fos is considered to be a transcription factor. Monitoring the nuclear expression of the c-Fos protein is a well-established and reliable technique to locate anatomically the functional neuronal activity. C-Fos immunohistochemistry is useful technique which enable 
to investigate the ability of the neurons in regulation of gene expression with changes to external stimulation (e.g., physiological and pathological and pharmacological). Fos expression is considered 'third-messenger' cellular signals $[25,26]$.

In our previous report we demonstrated that GBP-morphine combinational administration attenuated the acute morphine-induced c-Fos expression in rat nucleus accumbens [27] and striatum [28]. Nucleus accumbens showed dense projection from paraventricular nucleus (PVN). Moreover, all the major sources of inputs to the nucleus accumbens also receives neural projection from PVN. Projections from dopamine (DA) neurons of the ventral tegmental area (VTA) to the nucleus accumbens have been involved as a major functional neural circuit of the reinforcement caused by opioids [29-31].

Therefore, to investigate whether the hypothalamus is a possible neuro-anatomical target sites of GBP-morphine combined function, we examined the effects of co-administration of GBP and morphine on c-Fos expression in the rat hypothalamus a supraspinal part of the CNS.

\section{Methods}

We obtained approval from the Institutional Animal Care and Use Committee for this study. All experimental procedures were carried out in accordance with our institutional guidelines for the care and use of laboratory animals.

Male Sprague-Dawley rats $(180-200 \mathrm{~g})$ were divided in two groups. Five per group were housed provided with fixed $12 \mathrm{~h}$ light-dark cycle facility with free access to food and water at all times. Rats were acclimatized once daily in order to minimize stress for at least 5 days. Rats were exposured to the general handling and anesthesia procedures. Drugs used: anesthetic sodium pentobarbital $(50 \mathrm{mg} / \mathrm{kg}$ i.p.; CEVA Sante Animale, France), GBP (Sigma) and morphine (Sigma). First groups received $1 \mathrm{ml}$ dose of intraperitoneal injection (i.p.) of morphine $(10 \mathrm{mg} / \mathrm{kg})$. In second groups a single $1 \mathrm{ml}$ dose of GBP $(150 \mathrm{mg} / \mathrm{kg}$, i.p.) plus morphine $(10 \mathrm{mg} / \mathrm{kg}$, i.p. $)$ was administered. Control group received single $1 \mathrm{ml}$ dose of i.p. of normal saline (saline treated). At $90 \mathrm{~min}$ after i.p injections of saline and drugs under anesthesia animals were perfused with $4 \%$ paraformaldehyde. Brain tissues were removed. Serial sections of $40 \mu \mathrm{m}$ thick were prepared with a freezing microtome and kept in PBS at $4^{\circ} \mathrm{C}$. c-Fos protein immunocytochemistry was done using the peroxidase-antiperoxidase [27,28]. Sections were then incubated with rabbit antibody to c-Fos protein (1:4000, Santa Cruz Biotechnology Inc., CA, USA) in PBS with $0.3 \%$ Triton $\mathrm{X}-100$ for 3 days at $4^{\circ} \mathrm{C}$ followed by incubation for 1 day at $4^{\circ} \mathrm{C}$ in a goat anti-rabbit $\operatorname{IgG}(1: 2000$, E-Y Laboratories Inc., CA, USA) and then by the tertiary antibody, peroxidase-antiperoxidase (PAP) in a 1: 2000 dilution and incubated for 1 day at $4{ }^{\circ} \mathrm{C}$. The dilution buffer $[0.3 \%$ bovine serum albumin, $1 \%$ normal goat serum and $0.05 \%$ sodium azide] was used for the preparation of the working solution of the primary, secondary and tertiary antibodies. Sections were washed with PBS in between the incubation. For the identification of peroxidase color, the DAB method was used. The sections were incubated for $20 \mathrm{~min}$. at room temperature contain $0.02 \%$ diaminobenzidine and $0.003 \%$ hydrogen peroxide in $0.05 \mathrm{M}$ Tris- $\mathrm{HCl}$ - buffer, $\mathrm{pH} 7.6$ (THB). Sections were rinsed in THB, mounted onto gelatin-chrome alum-coated glass slides the air dried and dehydrated with ethanol. Sections were cleared in xylene, and then cover slipped. A separate immune reaction was performed in which the was omitted, no specific immunostaining was observed.

The sections were analyzed under a microscope and the labeled c-Fos-positive neurons per section were counted. Six sections per animal at the level of hypothalamus were used to analyze c-Fos immunoreactivity. c-Fos-positive neurons per slide was counted manually by a person with no knowledge experiment. Average number of c-Fos immunoreactive neurons for each animal was done. And means ( \pm standard deviation: SD) and statistics were performed for all groups. Paired $t$-test analysis was done. In statistical analysis differences at $\mathrm{p}<0.01$ were considered significant.

\section{Results}

At 90 min after morphine injection, an increase in c-Fos immunoreactive neurons was detected in the hypothalamus bilaterally [29,30].

In Figure 1, in the saline treated rats, the semi-quantitative analysis revealed the number of the c-Fos-positive neurons per section was $09 \pm 1.1$ in the right side and $11 \pm 1.3$ in the left side of the hypothalamus. Compared with the saline treated group $(\mathrm{p}<0.01)$, per section the number of $\mathrm{c}$-Fos-positive neurons in the hypothalamus was $211 \pm 2$ in the left side and $210 \pm 3$ per section in the right side. These results are in accordance with the previous reports $[29,30]$. 
(A)

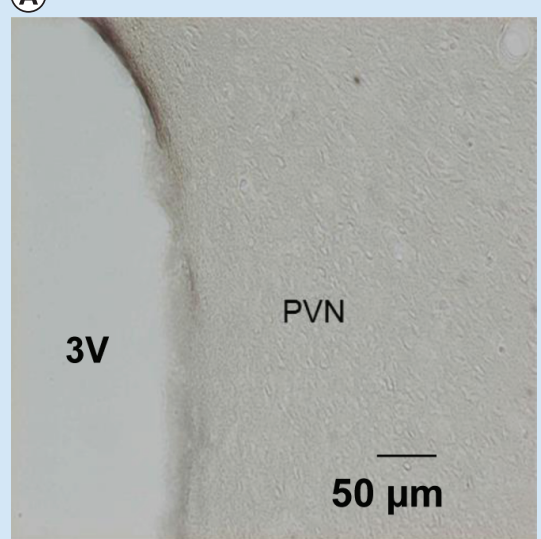

Saline treated
(B)

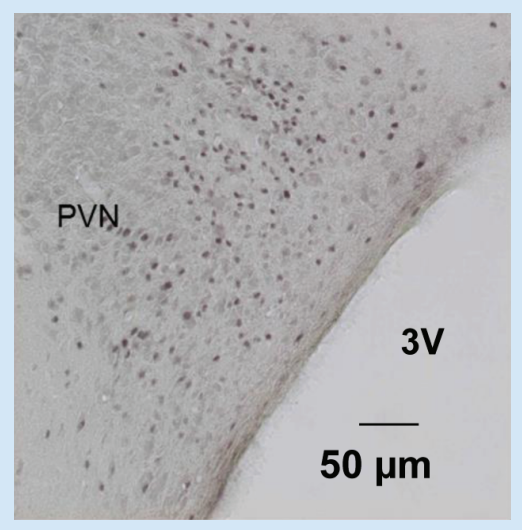

MOR treated

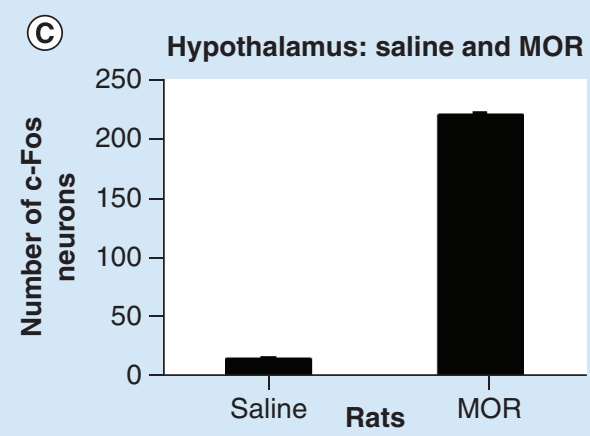

Figure 1. Photomicrographs showing the expression of c-Fos protein in the rat paraventricular nucleus of the hypothalamus. Compared with saline treated rats (A) increased in c-Fos expression was observed in rats of acute morphine administration ( $10 \mathrm{mg} / \mathrm{kg}$, i.p.) (B) $\mathrm{p}<0.01$. Nuclei immunoreactive for c-Fos protein appear as black staining. $3 \mathrm{~V}=$ third ventricle, scale bar, $50 \mu \mathrm{m}$. (C) A graphic showing the semi-quantitative analysis of c-Fos positive neurons in the PVN of the hypothalamus in rats. Compared with the saline treated rats acute administration (10 $\mathrm{mg} / \mathrm{kg}$ ) of morphine significantly increased number of c-Fos-positive neurons is observed in rats treated with acute morphine administration (10 mg/kg, i.p.). $\mathrm{p}<0.01$ as compared with saline treated and acute morphine injection. MOR: Morphine; PVN: Paraventricular nucleus.

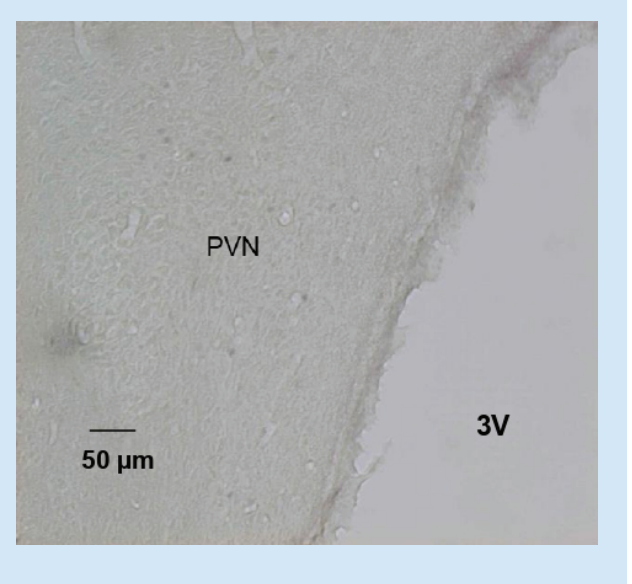

Figure 2. Photomicrographs showing the expression of c-Fos protein in the rat paraventricular nucleus of the hypothalamus. The elevated c-Fos expression induced by acute morphine administration (Figure 1B) is completely attenuated in rats receive co-injection of gabapentin (150 mg/kg, i.p.) and morphine $(10 \mathrm{mg} / \mathrm{kg}$, i.p.) (Figure 2$) \mathrm{p}<0.01$. Nuclei immunoreactive for c-Fos protein appear as black staining. Scale bar $=50 \mu \mathrm{m}$.

3V: Third ventricle; PVN: Paraventricular nucleus.

Figure 2, shows the acute morphine injection significantly increased the c-Fos immunoreactive neurons (Figure 1A) in the hypothalamus. Co-injection (i.p.) of GBP $(150 \mathrm{mg} / \mathrm{kg})$ with morphine $(10 \mathrm{mg} / \mathrm{ml})$ signif- 


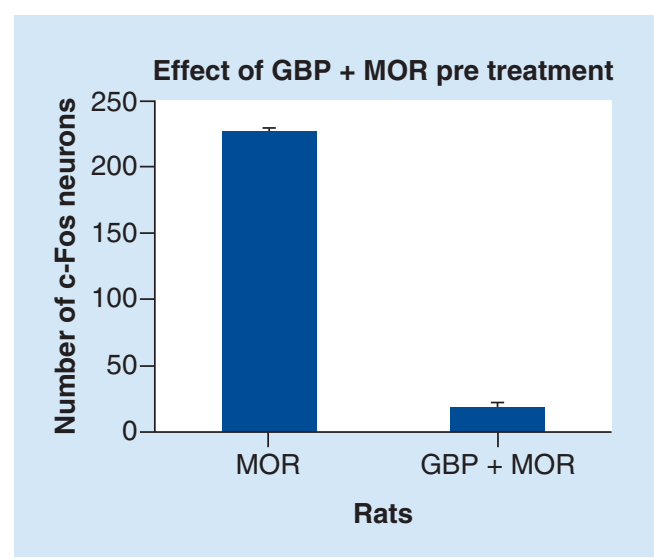

Figure 3. A graphic showing the semi-quantitative analysis of c-Fos-positive neurons in the paraventricular nucleus of the hypothalamus of the rats receive co-administration of gabapentin (150 mg/kg, i.p.) and morphine (10 mg/kg, i.p). Compared with the acute morphine administered rats the co-injection of GBP and morphine completely attenuated the elevated c-Fos expression induced by acute injection of morphine. $p<0.01$ vs acute morphine injection/co-administration of GBP and morphine. GBP: Gabapentin; MOR: Morphine.

icantly suppressed $(\mathrm{p}<0.01)$ acute morphine induced immunoreactive nerve cell bodies in the hypothalamus (Figure 2).

The semi-quantitative analysis in Figure 3, shows that at 90 min after co-injection of GBP $(150 \mathrm{mg} / \mathrm{kg})$ and morphine, the number of c-Fos protein-like immunoreactive nerve cell bodies in the hypothalamus $(10 \mathrm{mg} / \mathrm{kg})$ was $12 \pm 1.5$ in the right side and $14 \pm 1.6$ in the left side per section $(\mathrm{p}<0.01)$. However, compared with the co-administration of GBP with morphine, in acute morphine treated rats $(\mathrm{p}<0.01)$, per section the of c-Fospositive neurons in the hypothalamus was $228 \pm 2$ in the left side and $226 \pm 3$ in the right side $(\mathrm{p}<0.01)$. These results suggested that the hypothalamus was another possible functional site for GBP-morphine co-administration (i.p.). These data also indicated the neutralizing effect of combined therapeutic function of GBP with morphine in activated hypothalamus. The variability in c-Fos expression in various experimental groups seems extremely low demand further study to reveal this phenomenon.

\section{Discussion}

This study showed that, acute morphine $(10 \mathrm{mg} / \mathrm{ml})$ administration induced increase in c-Fos expression in hypothalamus was entirely neutralized by the combined administration (i.p.) of GBP $(150 \mathrm{mg} / \mathrm{kg})$ and morphine $(10 \mathrm{mg} / \mathrm{ml})$. The present results are in accordance with previous reports with respect to the administration of morphine induced expression of the c-Fos in different regions of the CNS in rat, including the hypothalamic PVN, striatum and nucleus accumbens [27-29].

Studies documented that even in an individual exposure to opioid caused chronic behavioral sensitization and subsequent neuroadaptation. This processes of morphine sensitization are believed to be involved for morphine dependence particularly for the enhanced craving for the drug [30]. It is noteworthy, to mention that the mechanism of GBP action is unknown [31].

Morphine abuse associated with a complex interaction of several adaptations take place in multiple neurotransmitter systems (N-methyl-D-aspartate [NMDA], mu receptors, DA). In addition, previous reports have clearly showed the existence of a operational interplay between the glutaminergic-DA-morphine systems [32-34]. Furthermore, it is noteworthy to mention that reports clearly showed that the expression of c-Fos was regulated and induced by mu receptors, NMDA receptors and DA D1. D2 receptors [35-37].

The expression of the mu-receptor located in the anterior hypothalamus, supraoptic (SON), the hypothalamic paraventricular nucleus (PVN), ventromedial, dorsomedial and arcuate nuclei of the hypothalamus [38-40]. The NMDA receptors expressed widely through the CNS such as striatum, prefrontal cortex, hippocampus, hypothalamus and amygdala [41-44]

Dopaminergic system is key for the expression of morphine sensitization. Report demonstrated that the origin of the DA fibers in the VTA (PVT) was not from VTA, however the DA neurons detected in the hypothalamus. Moreover, it was observed that the release of accumbens (NAc) DA was controlled by the opioids in the hypothalamic PVN thus indicated that this neural pathway from the PVN to the NAc might be the possible functional circuitry underlying morphine-induced behavior [45-47]. In our previous report, we demonstrated that GBP attenuated c-Fos expression induced by morphine in striatum, and in the nucleus accumbens $[28,29]$ therefore, present study indicated that GBP interplayed an unknown neuromudulatory mechanism to attenuate opioid induced c-Fos expression in between PVN- striatum - nucleus accumbens. 
Recent studies demonstrated the involvement of mu opioid, NMDA, D1/D2 receptors systems in the regulation of opioid induced sensitization and the development of morphine tolerance and dependence. Protein kinase $\mathrm{C}$ (PKC) is the main controlong enzyme that modulated the regulation of mu and DA (D1/D2) receptors. It is noteworthy to mention that GBP inhibited PKC signaling pathways [48-52]. Gabapentin also inhibited the spinal neuronal action of NMDA receptors [53-55].

Thus, present results strongly led us to speculate the possibility that GBP might have antagonism function on NMDA receptor-mu-receptor-DA receptor system.

Morphine binds with highest affinity to mu-receptor and the study substantiated that in mu-receptor knockout mice all its physiologic actions, including analgesia, tolerance reward effects and withdrawal symptoms were absent. Previous report on mu opioid receptor autoradiography demonstrated that, morphine-sensitization was significant increase in the hypothalamus (200\%) and nucleus accumbens (16\%). This study also demonstrated that the cAMP, which is the main second messenger system responsible for the linking to the opioid receptor levels were significantly increased in opioid sensitized animals (70\% versus controls) including NAc and hypothalamus [56].

Morphine treatment has been shown to upregulate PKC pathway in several brain areas. PKC is a key regulatory enzyme that modulated the regulation of mu receptors. Several studies indicated that up-regulation of PKC as one of the molecular mechanisms of opioid tolerance and dependence. Moreover, the study demonstrated that morphine induced enhancement of the hypothalamus-pituitary-adrenocortical axis activity during morphine withdrawal was blocked by selective PKC inhibitor [48,49].

It is noteworthy to mention that GBP inhibited PKC signaling pathways. More importantly, PKC activates expression of c-Fos [50,51]. Therefore, the c-Fos expression induced by the administration of acute morphine, which was neutralized by the combined administration of GBP-morphine, observed in our present study as well as our previous reports $[27,28]$ might indicate the possible regulatory function of GBP on PKC through an unknown neurochemical circuit. Thus present result and previous reports have also raised the speculation of the possible existence of neuromodulatory circuit $(s)$ to regulate increased in mu opioid receptor sensitization in hypothalamus through GPB-PKC signaling pathways. That is GPB regulated antagonism system of mu opioid receptor sensitization. GBP might have regulatory effect on mu receptors antagonism through PKC signaling system.

Recent studies demonstrated the implication of DA receptors in the regulation of opioid sensitization of nucleus accumbens (NAc) in mice and that the PKC modulated DA receptors coupling to its G-protein [52].

Previous reports showed that opioid treatment altered the expression of the NMDA receptor in the hypothalamus $[57,58]$ and NMDA receptor antagonist and intrathecal gabapentin inhibited the morphine induced development of spinal tolerance and dependence [59,60]. Recent evidences demonstrated that gabapentin inhibited the spinal neuronal action of NMDA receptors [53-55]. It was postulated that the spinal NMDA receptors antagonism by GBP might have played a role in blocking morphine tolerance and enhance morphine analgesia, the interference of its supra-spinal circuits is not known. Moreover, the effect of GBP on hypothalamic NMDA receptor subunits are not known. Interestingly, one study demonstrated that, GBP increased NMDA currents in GABAergic neurons thus exerted its antinociceptive action by the activity of GABAergic inhibitory neurons [61].

More interestingly, report showed that opioids administration indirectly activated NMDA receptors by stimulation of $\mu$-opioid receptors. D1 receptors activated the cyclase response element (CRE) and NMDA receptors activated the serum response element (SRE) in the c-fos promoter [62]. In addition, the study demonstrated that simultaneous trigger of NMDA and D1 receptors induced Fos in striatum [63].

Thus, above reports strongly led us to speculate the possibility that GBP might have antagonism function on NMDA receptor and/or mu-receptor and/or DA receptor system.

In light of this evidence evidences the involvement of GBP regulated morphine receptors antagonism mechanism' that contribute to a common neuromodulatory circuit of NMDA receptor-mu receptor-DA receptor system to neutralize the morphine induced c-Fos expression observed this study cannot be ruled out.

Thus this, present study strongly indicates to reveal the underlying functional modulatory/inhibitory mechanism of gabapentin to neutralize supraspinal morphine sensitization the following receptor signaling systems: PKC-DA receptors, PKC-NMDA receptors, PKC-mu-opioid receptors or a common antagonism circuit linked to above three systems. The results of this study strongly indicates that understanding the link between GBP-PKC-receptors of morphine sensitization circuits might be a potential target for the therapeutic intervention of opioid induce side effects and also to potentiate morphine analgesia [63]. 
Evidences based on clinical studies showed that the combination of morphine and gabapentin yielded better analgesia than morphine alone with safety [64,65]. Recent clinical study documented that co administration of opioid and GBP provided reduction in opioid use and complications this study also noticed the clinical benefit including critical respiratory failure [66]. Recently, increasing number of clinical reports on efficacy of gabapentin (pre and post-operative) on 'morphine consumption' and in 'reducing pain intensity' have been documented [64-68]. Thus the present study strongly indicated to reveal the functional molecular singling circuits of 'combination of morphine and gabapentin' observed in clinical reports.

The mechanism(s) of action that interpret the wide range of effects of gabapentin is not known. More importantly, the molecular evidence for supraspinal function of GBP remains a puzzling [69]. To confirm this observation further studies are warranted, as the hypothalamus, striatum and nucleus accumbens contains a various kind of neuropeptides generally possess different neuromodulatory function. It is noteworthy to mention that c-Fos expression might also be induced in the CNS by trans-synoptically [70]. Therefore, to dig the therapeutic effectiveness of GBP-morphine interaction to neutralize c-Fos over-expression in the hypothalamus (present study), striatum [29] and neuclus accumbens [28], it is crucial to reveal the underlying molecular signaling of this c-Fos expression.

As Fos expression is an indicator of neuronal activity to the level of gene regulation [25]. We cautiously suggest that gabapentin neuromodulate and or antagonize the receptor regulatory machinery/systems of morphine sensitization that interplay roles between hypothalamus-striatum-nucleus accumbens through an unknown neuronal circuit [3537,71 .

Present results will be useful to obtain more details in the underlying mechanisms of GBP-morphine interaction to attenue the acute morphine sensitization of 'hypothalamus- striatum-nucleus accumbens' circuits.

In conclusion, we cautiously suggest a hypothetical model to be tested that GBP neuromodulate and/or antagonize the receptor regulatory machinery of morphine sensitization' through an unknown neuronal circuit which might be taste able for 'drug discovery of morphine abuse.

\section{Summary points}

- Hypothalmus may be the site of 'gabapentin (GBP) - morphine combinational function' to prevent, to neutralize morphine side effects.

- Gabapentin might neuromodulate and/ or antagonize the 'receptor regulatory machinery of morphine sensitization' through an unknown neuronal circuit.

- Gabapentin might interplay roles between hypothalamus - striatum - nucleus accumbens through an unknown neuronal circuit to antagonize morphine sensitization.

- 'GBP-PKC-receptors of morphine sensitizations' circuits could be a potential target for the treatment of opioid induce side effects.

- 'GBP-PKC-receptors of morphine sensitizations' circuits could be a potential target to potentiate morphine analgesia.

- GBP might have antagonism function on $\mathrm{N}$-methyl-D-aspartate receptor.

- GBP might have antagonism function on dopamine receptor system.

- GBP might have antagonism function on mu- receptor system.

\section{Acknowledgements}

We thank Kazi Rasheeq Azhan Alvi, Toyo University, Tokyo, Japan, for his generous support with English editing.

Financial \& competing interest disclosure

This work was supported by a grant form Skim Geran Penyelidikan Fundamental (FRGS), University Teknologi MARA (Grant \# 600-RMI/FRGS 5/3 (115/2014). The authors have no other relevant affiliations or financial involvement with any organization or entity with a financial interest in or financial conflict with the subject matter or materials discussed in the manuscript. This includes employment, consultancies, honoraria, stock ownership or options, expert testimony, grants or patents received or pending, or royalties.

No writing assistance was utilized in the production of this manuscript. 


\section{Open access}

This work is licensed under the Creative Commons Attribution-NonCommercial-NoDerivatives 4.0 Unported License. To view a copy of this license, visit: http://creativecommons.org/licenses/by-nc-nd/4.0/

\section{References}

Papers of special note have been highlighted as: $\bullet \bullet$ of considerable interest

1. Mao J. Opioid-induced abnormal pain sensitivity: implications in clinical opioid therapy. Pain 100, 213-217 (2002).

2. Koob GF, Sanna PP, Bloom FE. Neuroscience of addiction. Neuron 21, 467-476 (1998).

3. Ren X, Noda Y, Mamiya T et al. A neuroactive steroid, dehydroepiandrosterone sulfate, prevents the development of morphine dependence and tolerance via c-fos expression linked to the extracellular signal-regulated protein kinase. Behav. Brain Res. 152, 243-250 (2004).

4. Nestler EJ. Molecular basis of long-term plasticity underlying addiction. Nat. Rev. Neurosci. 2, 119-128 (2001).

5. Nestler EJ. Molecular neurobiology of addiction. Am. J. Addict. 10, 201-217 (2001).

6. Nestler EJ, Aghajanian GK. Molecular and cellular basis of addiction. Science 278, 58-63 (1997).

7. Gilron I. Is gabapentin a "Broad-spectrum" analgesic? Anesthesiology 97, 537-539 (2002).

8. Chen SR, Pan HL. Effect of systemic and intrathecal gabapentin on allodynia in a new rat model of postherpetic neuralgia. Brain Res. 1042, 108-113 (2005).

9. Pollack MH, Matthews J, Scott EL. Gabapentin as a potential treatment for anxiety disorders. Am. J. Psychiatry 155, 992-993 (1998).

10. Tanabe M, Takasu K, Kasuya N et al. Role of descending noradrenergic system and spinal alpha2-adrenergic receptors in the effects of gabapentin on thermal and mechanical nociception after partial nerve injury in the mouse. Br. J. Pharmacol. 144, 703-714 (2005).

11. Patel MK, Gonzalez MI, Bramwell S et al. Gabapentin inhibits excitatory synaptic transmission in the hyperalgesic spinal cord. Br. J. Pharmacol. 130, 1731-34 (2000).

12. Kaneko M, Mestre C, Sanchez EH, Hammond DL. Intrathecally administered gabapentin inhibits formalin-evoked nociception and the expression of Fos-like immunoreactivity in the spinal cord of the rat. J. Pharmacol. Exp. Ther. 292, 743-751 (2000).

13. Hwang JH, Yaksh TL. Effect of subarachnoid gabapentin on tactile-evoked allodynia in a surgically induced neuropathic pain model in the rat. Reg. Anesth. 22, 249-256 (1997).

14. Gilron I, Biederman J, Jhamandas K, Hong M. Gabapentin blocks and reverses antinociceptive morphine tolerance in the rat paw-pressure and tail-flick tests. Anesthesiology 98, 1288-1292 (2003).

15. Field MJ, Oles RJ, Lewis AS et al. Gabapentin (neurontin) and S-(+)-3-isobutylgaba represent a novel class of selective antihyperalgesic agents. Br. J. Pharmacol. 121(8), 1513-1522 (1997).

16. Pakulska W, Czarnecka E. The effect of gabapentin on antinociceptive action of analgesics. Acta Pol. Pharm. 6, 393-400 (2004).

17. Hansen C, Gilron I, Hong M. The effects of intrathecal gabapentin on spinal morphine tolerance in the rat tail-flick and paw pressure tests. Anesth. Analg. 99, 1180-1184 (2004).

18. Gilron I, Bailey JM, Tu D et al. Morphine, gabapentin, or their combination for neuropathic pain. N. Engl. J. Med. 352, 1324-1334 (2005).

-. Treatment of neuropathic pain with the combination of gabapentin and morphine results in less pain than treatment with either gabapentin or morphine as a single agent, the maximal tolerated doses of morphine and gabapentin were significantly lower with the combination than in treatment with each as a single agent, which suggested an additive interaction.

19. Smiley MM, Lu Y, Vera-Portocarrero LP et al. Intrathecal gabapentin enhances the analgesic effects of subtherapeutic dose morphine in a rat experimental pancreatitis model. Anesthesiology 101, 759-765 (2004).

20. Matthews EA, Dickenson AH. A combination of gabapentin and morphine mediates enhanced inhibitory effects on dorsal horn neuronal responses in a rat model of neuropathy. Anesthesiology 96, 633-640 (2002).

21. Martinez-Raga J, Sabater A, Perez-Galvez B et al. Add-on gabapentin in the treatment of opiate withdrawal. Prog. Neuropsychopharmacol. Biol. Psychiatry 28, 599-601 (2004).

22. Andrews $\mathrm{N}$, Loomis S, Blake R et al. Effect of gabapentin-like compounds on development and maintenance of morphine-induced conditioned place preference. Psychopharmacology (Berl). 157, 381-387 (2001).

23. Dierking G, Duedahl TH, Rasmussen ML et al. Effects of gabapentin on postoperative morphine consumption and pain after abdominal hysterectomy: a randomized, double-blind trial. Acta Anaesthesiol. Scand. 48, 322-327 (2004).

24. Mikkelsen S, Hilsted KL, Andersen PJ, Hansen M, Henriksen J, Dahl JB et al. The effect of gabapentin on post-operative pain following tonsillectomy in adults. Acta Anaesthesiol. Scand. 50, 809-815 (2006).

25. Hughes $P$, Dragunow M. Induction of immediate-early genes and the control of neurotransmitter-regulated gene expression within the nervous system. Pharmacol. Rev. 47, 133-178 (1995).

26. Kovács KJ. c-Fos as a transcription factor: a stressful (re)view from a functional map. Neurochem. Int. 33(4), 287-297 (1998). 
-• c-Fos as a transcription factor and as a functional marker of activated neurons and has become the most widely used powerful tool to delineate individual neurons as well as extended circuitries that are responsive to wide variety of external stimuli.

27. Kazi JA, Abu-Hassan MI. Gabapentin completely attenuated the acute morphine-induced c-Fos expression in the rat nucleus accumbens. J. Mol. Neurosci. 45(2), 101-109 (2011).

-. Nucleus accumbens shell is one of the functional neuro-anatomical site of gabapentin-morphine combination action to neutralize the acute activation of morphine.

28. Kazi JA, Gee CF. Gabapentin completely attenuated the acute morphine induced c-Fos expression in the rat striatum. J. Mol. Neurosci. 32(1), 47-52 (2007).

-. Striatum is the functional site for the nutalization of acute morphine sensitization by the combinational action of gabapentin-morphine.

29. Chang SL, Squinto SP, Harlan RE. Morphine activation of c-Fos expression in rat brain. Biochem. Biophys. Res. Commun. 157, 698-704 (1988).

30. Vanderschuren LJ, De Vries TJ, Wardeh G et al. A single exposure to morphine induces long-lasting behavioural and neurochemical sensitization in rats. Eur. J. Neurosci. 14, 1533-1538 (2001).

31. Cheng JK, Chiou LC. Mechanisms of the antinociceptive action of gabapentin. J. Pharmacol. Sci. 100, 471-486 (2006).

32. Chase TN, Bibbiani F, Oh JD. Striatal glutamatergic mechanisms and extrapyramidal movement disorders. Neurotox. Res. 5, 139-146 (2003).

33. Chase TN, Oh JD. Striatal dopamine- and glutamate-mediated dysregulation in experimental parkinsonism. Trends Neurosci. 23, S86-S91 (2000).

34. Bodnar RJ, Klein GE. Endogenous opiates and behaviour. 2005. Peptides 27, 3391-3478 (2006).

35. Vertes RP, Hoover WB. Projections of the paraventricular and paratenial nuclei of the dorsal midline thalamus in the rat. J. Comp. Neurol. 508, 212-237 (2008).

36. Li S, Kirouac GJ. Projections from the paraventricular nucleus of the thalamus to the forebrain, with special emphasis on the extended amygdala. J. Comp. Neurol. 506, 263-287 (2008).

37. Laorden ML, Castells MT, Martínez MD et al. Activation of c-fos expression in hypothalamic nuclei by mu- and kappa receptoragonists: correlation with catecholaminergic activity in the hypothalamic paraventricular nucleus. Endocrinology. 141(4), 1366-1376 (2000).

38. Zheng SX, Bosch MA, Rønnekleiv OK. mu-opioid receptor mRNA expression in identified hypothalamic neurons. J. Comp. Neurol. 487(3), 332-344 (2005).

39. Mansour A, Fox CA, Burke S et al. delta, and kappa opioid receptor mRNA expression in the rat CNS: an in situ hybridization study. J. Comp. Neurol. 350, 412-438 (1994).

40. Mansour A, Hoversten MT, Taylor LP et al. The cloned $\mu, \delta$ and $\kappa$ receptors and their endogenous ligands: evidence for two opioid peptide recognition cores. Brain Res. 700, 89-98 (1995).

41. Missale C, Fiorentini C, Busi C et al. The NMDA/D1 receptor complex as a new target in drug development. Curr. Top Med. Chem. 6, 801-808 (2006).

42. Nabeshima T, Mouri A, Murai R, Noda Y. Animal model of schizophrenia: dysfunction of NMDA receptor-signaling in mice following withdrawal from repeated administration of phencyclidine. Ann. N. Y. Acad. Sci. 1086, 160-168 (2006).

43. Aguilar E, Tena-Sempere M, Pinilla L. Role of excitatory amino acids in the control of growth hormone secretion. Endocrine 28, 295-302 (2005).

44. Bajo M, Crawford EF, Roberto $\mathrm{M}$ et al. Chronic morphine treatment alters expression of N-methyl-D-aspartate receptor subunits in the extended amygdala. J. Neurosci. Res. 83, 532-537 (2006).

45. Li Sa, Shi Y, Kirouac Gilbert J. The hypothalamus and periaqueductal gray are the sources of dopamine fibers in the paraventricular nucleus of the thalamus in the rat. Front Neuroanat. 8, 136 (2014).

46. Nunez C, Földes A, Laorden ML et al. Activation of stress-related hypothalamic neuropeptide gene expression during morphine withdrawal. J. Neurochem. 101(4), 1060-1071 (2007).

47. Yao X, Xue B. Effects of morphine dependence on the levels of neurosteroids in rat brain. Acta Pharm. Sin. 40(11), 1037-1040 (2005).

48. Nestler EJ. Molecular mechanism of drug addiction. J. Neurosci. 12, 2439-2450 (1992).

49. Cerezo M, Laorden ML, Milanés MV. Inhibition of protein kinase $\mathrm{C}$ but not protein kinase $\mathrm{A}$ attenuates morphine withdrawal excitation of rat hypothalamus-pituitary-adrenal axis. Eur. J. Pharmacol. 452(1), 57-66 (2002).

50. Zhang YB, Guo ZD, Li MY et al. Gabapentin effects on PKC-ERK1/2 signaling in the spinal cord of rats with formalin-induced visceral inflammatory pain. PLoS One 10(10), e0141142 (2015).

-• A novel mechanism of gabapentin-mediated suppression of protein kinase $\mathrm{C}$ signaling pathway.

51. Yeh CY, Chung SC, Tseng FL et al. Biphasic effects of chronic intrathecal gabapentin administration on the expression of protein kinase C gamma in the spinal cord of neuropathic pain rats. Acta Anaesthesiol. Taiwan 49(4), 144-148 (2011). 
52. Pollock J, Kornetsky C. Evidence for the role of dopamine D1 receptors in morphine induced stereotypic behaviour. Neurosci. Lett. 102, 291-296 (1989).

53. Swartzwelder HS, Park MH, Acheson S. Adolescent ethanol exposure enhances NMDA receptor-mediated currents in hippocampal neurons: reversal by gabapentin. Sci. Rep. 7(1), 13133 (2017).

54. Matsumoto A, Arisaka H, Hosokawa $Y$ et al. Effect of carbamazepine and gabapentin on excitability in the trigeminal subnucleus caudalis of neonatal rats using a voltage-sensitive dye imaging technique. Biol. Res. 48(1), 36 (2015).

-. Gabapentin may act by blocking NMDA receptors in the Sp5c, which contributes to its anti-hypersensitivity in neuropathic pain.

55. Kim YS, Chang HK, Lee JW et al. Protective effect of gabapentin on $N$-methyl-D-aspartate-induced excitotoxicity in rat hippocampal CA1 neurons. J. Pharmacol. Sci. 109, 144-147 (2009).

56. Viganò D, Rubino T, Di Chiara G et al. Mu opioid receptor signaling in morphine sensitization. Neuroscience 117(4), 921-929 (2003).

57. Zhu H, Jang CG, Ma T et al. Region specific expression of NMDA receptor NR1 subunit mRNA in hypothalamus and pons following chronic morphine treatment. Eur. J. Pharmacol. 365(1), 47-54 (1999).

58. Zhu H, Brodsky M, Gorman AL, Inturrisi CE. Region-specific changes in NMDA receptor mRNA induced by chronic morphine treatment are prevented by the co-administration of the competitive NMDA receptor antagonist LY274614. Brain Res. Mol. Brain Res. 114(2), 154-162 (2003).

59. Trujillo KA, Akil H. The NMDA receptor antagonist MK-801 increases morphine catalepsy and lethality. Pharmacol. Biochem. Behav. 38(3), 673-675 (1991a).

60. Trujillo KA, Akil H. Inhibition of morphine tolerance and dependence by the NMDA receptor antagonist MK-801. Science 251, 85-87 (1991b).

61. Gu Y, Huang LY. Gabapentin potentiates N-methyl-D-aspartate receptor mediated currents in rat GABAergic dorsal horn neurons. Neurosci. Lett. 324(3), 177-180 (2002).

62. Bading H, Ginty DD, Greenberg ME. Regulation of gene expression in hippocampal neurons by distinct calcium signalling pathways. Science 260, 181-186 (1993).

63. Sharp FR, Liu J, Nickolenko J, Bontempi B. NMDA and D1 receptors mediate induction of c-fos and junB genes in striatum following morphine administration: implications for studies of memory. Behav. Brain Res. 66(1-2), 225-230 (1995).

64. de Leeuw TG, Mangiarini L, Lundin R et al. GAPP consortium. Gabapentin as add-on to morphine for severe neuropathic or mixed pain in children from age 3 months to 18 years - evaluation of the safety, pharmacokinetics, and efficacy of a new gabapentin liquid formulation: study protocol for a randomized controlled trial. Trials 20(1), 49 (2019).

-. First randomized controlled trial study on the effectiveness of the combination therapy morphine and gabapentin for pain in children which provided evidence that the combination of morphine and gabapentin reported better analgesia than morphine alone and safe.

65. Jang JS, Kwon Y, Hwang SM et al. Comparison of the efficacy of a gabapentinoid with an opioid versus an opioid alone in patients with spinal cord stimulation. Pain Phys. 21(4), E429-E434 (2018).

66. Cozowicz C, Poeran J, Zubizarreta $\mathrm{N}$ et al. Non-opioid analgesic modes of pain management are associated with reduced postoperative complications and resource utilisation: a retrospective study of obstructive sleep apnoea patients undergoing elective joint arthroplasty. BrJ Anaesth. 122(1), 131-140 (2019).

67. Barker JC, DiBartola K, Wee C, Andonian N, Abdel-Rasoul M, Lowery D, Janis JE et al. Preoperative multimodal analgesia decreases postanesthesia care unit narcotic use and pain scores in outpatient breast surgery. Plast. Reconstr. Surg. 142(4), 443e-450e (2018).

68. Jiang Y, Li J, Lin $\mathrm{H}$ et al. The efficacy of gabapentin in reducing pain intensity and morphine consumption after breast cancer surgery: a meta-analysis. Medicine (Baltimore) 97(38), e11581 (2018).

-• Preoperative use of gabapentin was able to reduce acute and chronic postoperative pain, a significantly reduction of total morphine consumption and the occurrence of nausea following breast cancer surgery.

69. Taylor CP, Gee NS, Su TZ et al. A summary of the mechanistic hypothesis of gabapentin pharmacology. Epilepsy Res. 29, 233-249 (1998).

70. Hirakawa M, Kawata M. Distribution pattern of c-Fos expression induced by sciatic nerve sectioning in the rat central nervous system. J. Hirnforsch. 34, 431-434 (1993).

71. Garcia MM, Anderson AT, Edwards R, Harlan RE. Morphine induction of c-fos expression in the rat forebrain through glutamatergic mechanisms: role of non-n-methyl-D-aspartate receptors. Neuroscience. 119, 787-794 (2003). 
